\title{
Territorios interiores y práctica de espacios en Fabio Morábito
}

\author{
Adalberto Mejía \\ Université Paul Valéry - Montpellier III
}

Resumen: Este artículo aborda las diferentes prácticas de espacio dentro de las obras Lotes baldíos (2001) y También Berlín se olvida (2004), del escritor mexicano Fabio Morábito (1955) quien, a través de una voz autobiográfica que va de la poesía al cuento, explora su experiencia nómada en ciudades como Alejandría, Milán, Berlín o la Ciudad de México. El autor reflexiona sobre la interacción de su lengua materna, de su identidad y de su memoria en relación con esos territorios interiores. Esta propuesta temática confirma los importantes vínculos con el espacio geográfico en México (la representación en códices prehispánicos o en las crónicas de la conquista, son antecedentes). Desde la geocrítica y las nociones de mapmaker y de navegación biográfica, se busca aportar otro enfoque al tema del espacio en Morábito.

Palabras clave: Prácticas de espacio, geocrítica, mapmaker, navegación biográfica

Résumé: Cet article aborde les différentes pratiques d'espace dans les œuvres Lotes baldíos (2001) et También Berlín se olvida (2004), de l'écrivain mexicain Fabio Morábito (1955) qui, à travers une voix autobiographique qui va de la poésie à la nouvelle, explore son expérience nomade dans des villes comme Alexandrie, Milan, Berlin et la ville de Mexico. L'auteur réfléchit sur l'interaction de sa langue maternelle, de son identité et de sa mémoire par rapport à ces arrière-pays. Cette proposition thématique confirme qu'au Mexique il y a des liens importants avec l'espace géographique (la représentation dans des codex préhispaniques ou dans des chroniques de la conquête, sont des antécédents). Depuis la géocritique et les notions mapmaker et navigation biographique, l'objectif est de donner une autre vision sur le sujet de l'espace chez Morábito.

Mots-clés: Pratiques d'espace, géocritique, mapmaker, navigation biographique 


\section{Introducción}

En Cuaderno del Nómada ${ }^{1}$ el poeta mexicano Tomás Segovia realizó una apología a ese ser de intemperie que vive de trayecto en trayecto, refiriéndose a él de la siguiente manera: "Nacido en los caminos, su destello es saber que todos han venido sin saberlo de otro sitio, que donde ponen su origen es allá donde empieza su ignorancia, que se hermanan de otro modo que el que creen..." (2000: 421). En esta suerte de bitácora nómada, Segovia hace énfasis en el hecho manifiesto de la experiencia y de la percepción en el desplazamiento migratorio. Agrega que el nómada "ha aprendido a modelar [...] un lenguaje de huellas" (ídem: 420), o que "sólo se arraiga en una tierra cuando la transitan sus caminos" (ídem: 426).

Este ejemplo ilustra dos perspectivas teóricas cuya contribución a los estudios sobre el espacio y la experiencia migratoria se da desde un enfoque compartido por el campo literario, el filosófico y el de los estudios culturales. Con la presentación de tales perspectivas se busca no únicamente dirigir los ejes del presente trabajo, sino además reflexionar, en una plano más general, sobre el papel que tienen los estudios de espacialidad y las relaciones próximas entre literatura, geografía, migración y autobiografía. La primera perspectiva se trata de la aportación dada por Michel de Certeau en L'invention du quotidien. 1. Arts de faire (1980), quien se refiere a la noción de "prácticas de espacios"2 como la realización de un discurso o topos narrativo que relata la interacción con el espacio y el desplazamiento en él. Tal narrativa es posible gracias a la lectura de ese "lugar palimpsesto" y a lo que él denomina figures cheminatoires ou piétonnières [figuras caminantes o peatonales], es decir, figuras retóricas que apuntan a una pretendida gramática del espacio, mismas que permitirían metaforizar y contar dicha experiencia desde la subjetividad individual o colectiva.

Bajo la misma reflexión, Robert Tally ofrece un argumento complementario en su libro Spatiality (2013). Ahí, Tally se refiere a la idea del mapmaker ${ }^{3}$ como aquel individuo que interactúa con el espacio y que se desplaza en él, que lo interpreta, lo representa y lo reconstruye. Este rol de "hacedor de mapas", visto desde del papel del escritor y del lector, 
podría promover la elaboración de una cartografía literaria aplicable a trabajos narrativos, visuales o culturales. Así, el mapeo de los espacios sería una herramienta para abordar la vivencia migratoria, geográfica y espacial desde un ámbito ficcional e incluso social.

En este sentido se presenta la segunda perspectiva. Al migrar, ¿a dónde se pertenece realmente?, ¿qué mecanismos individuales o colectivos permiten los sentidos de apropiación y pertenencia respecto a uno o diversos espacios?, ¿cómo podría elaborarse un trabajo autobiográfico desde la mirada de un mapmaker en desplazamiento? En su artículo titulado "Multiple Belonging and the Challenges to Biographic Navigation"4 (2013), la académica Joanna Pfaff-Czarnecka establece la posibilidad de una "navegación biográfica" que pueda encontrar una "pertenencia múltiple". En otras palabras, un marco biográfico continuamente construido a través de sus propios trayectos o desplazamientos migratorios, y que se enfrenta a una constelación de colectividades y de espacios, negociando diferentes procesos y esferas de pertenencia.

El ángulo sociológico que toma Pfaff-Czarnecka complementa desde otra postura las aproximaciones a los estudios espaciales, al mismo tiempo que pone de relieve la percepción y la representación entre los espacios imaginarios y los espacios dichos reales o "geoespacios"5. Y en esta coyuntura es necesario detenerse. El hecho de interactuar con el espacio, de crear cartografías personales o territorios interiores, encuentra muy diversas manifestaciones y expresiones. Así, retomando a Tomás Segovia en las primeras líneas, el nómada ha aprendido a modelar un lenguaje de huellas y a arraigarse en una pluralidad de caminos. ¿Sería esto una posible entrada hacia una escritura migrante, habitada de memorias dispersas en el trayecto, de lenguas y de espacios desconocidos?

\section{Prácticas del espacio en México: algunos antecedentes.}

De esta correlación entre práctica de espacios, su representación y el desplazamiento en ellos, se distingue una añeja tradición que concierne a la percepción y a la pertenencia del espacio mismo dentro de la cultura mexicana. Desde la época precolombina, en civilizaciones como la maya, la azteca o la mixteca, existió un gran interés por el espacio y un tipo de interacción con él cercano a un ámbito sagrado. De manera 
general, en esas civilizaciones la representación del espacio está cargada de valores religiosos, morales, históricos; recurrían a metáforas para abordar tanto el espacio real y el imaginario; para la orientación, el norte no era la referencia, sino la diversidad de puntos cardinales según la ubicación de cierto entorno o espacio sagrado, permitiendo construir y leer narrativas de acuerdo con la orientación dada.

Los especialistas coinciden al destacar los valiosos conocimientos geográficos y la posición privilegiada de una "narración espacial” para presentar hechos históricos, batallas y migraciones a través de un lenguaje iconográfico. En los pocos códices prehispánicos 6 conservados se aprecia la concepción de un espacio que se encuentra entre lo real y lo imaginario, construido a través de metáforas y con otro tipo de ejes (como el Este-Oeste para representar el transcurso del nacimiento a la muerte). Sin duda, una percepción distinta a la ya consolidada en Occidente y que sería impuesta de manera general durante el proceso de conquista en el siglo XVI. Un ejemplo es el Codex Xolotl, que se concentra en la representación panorámica del valle central de México en el momento de una invasión. Este códice recurre a distorsiones del espacio para adaptarlo a circunstancias políticas y migratorias en movimiento, saturando de datos históricos la representación pictográfica, aspecto que, se deduce, revela cierto “temor al vacío” propio de estas civilizaciones.

Sin embargo, el despliegue de estas manifestaciones y expresiones vinculadas con el espacio ha variado, por supuesto, en el devenir de contextos culturales, históricos y estéticos. Una vez transcurrido el efecto inmediato del llamado "descubrimiento de América" y, en el caso específico de México, de los años de colonización, la percepción del espacio cambió de forma radical. El proceso de percepción y práctica de ese espacio descubierto pasó a manos de los llamados Cronistas de Indias, como las Cartas de relación (1522) de Hernán Cortés, la Historia Chichimeca (1610-1640) de Fernando de Alva Ixtlilxochitl, o la Historia verdadera de la conquista de la Nueva España (1632) de Bernal Díaz del Castillo, o ya en el siglo XVIII, Breve y compendiosa narración de la Ciudad de México (1777) de Juan de Viera, en el que comenta los días de la capital mexicana durante la época del virreinato.

Si bien las anteriores han sido consideradas como parte de las primeras 
manifestaciones literarias en prosa en México, en el transcurso de cuatro siglos de sincretismo cultural este tipo de manifestaciones darían giros importantes en cuanto a estilos literarios, temas, otras formas de percepción del espacio y de experiencia migratoria. En el siglo XIX se encuentran por ejemplo la obra colectiva Antonino y Anita o Los nuevos misterios de México $^{7}$ (1851) que, bajo prácticas ensayísticas y ficcionales, combina textos e imágenes sobre la ciudad, o las Impresiones de viaje. Traducción libre del diario de un zuavo, encontrado en su mochila, en la acción de Barranca Seca ${ }^{8}$ (1862) de Guillermo Prieto, que presenta una crónica a través de la figura de un soldado al que le interesa retratar la historia y las diferentes topografías que recorre (como por ejemplo, la región del Golfo de México, lo cual le hace pensar en el llamado “descubrimiento del Nuevo Mundo").

En este sentido, a inicios del siglo XX algunas expresiones literarias continuaron explorando el espacio de valle de Tenochtitlan, pero ahora bajo el peso de una dolorosa máscara urbana nombrada Ciudad de México. Estas expresiones sobre el tema se multiplicaron, ofreciendo otros panoramas identitarios y ricas cartografías literarias para comprender el espacio en cuestión, para redefinirlo y para mirar el desplazamiento de un pasado y un presente cultural. De esta forma, a lo largo del siglo XX y lo que va del XXI, se ha asistido a otras formas de aproximación espacial al paisaje mexicano.

En una brevísima mención, algunos ejemplos son La visión de Anáhuac (1519) (1915) de Alfonso de Reyes, la primera novela de Francisco Tario, Aquí abajo (1941), el poema Declaración de odio (1944) de Efraín Huerta, Los días enmascarados (1954) de Carlos Fuentes, Pedro Páramo (1955) de Juan Rulfo, el poemario Teotihuacán, y 13 de agosto: ruina de Tenochtitlán (1965) de Carlos Pellicer, las numerosas crónicas de Carlos Monsiváis en por ejemplo Días de guardar (1970) o en Los rituales del caos (1995), Los paseos de la ciudad de México (1974) de Salvador Novo, uno de los máximos poemas de José Emilio Pacheco, Alta traición (1969) o su novela Batallas en el desierto (1981), o La tercera Tenochtitlan (1983) del poeta Eduardo Lizalde. ${ }^{9}$

Por supuesto, cada una de estas obras contiene un tratamiento distinto acerca de la Ciudad de México y de otras topografías mexicanas, según la circunstancia dada: el proceso de la revolución mexicana, la guerra de los Cristeros, el boom económico en la década de los 
cuarenta, la matanza estudiantil del 68, o la transición democrática a fin de siglo. Estas y otras prácticas literarias construyeron el espacio mexicano desde la crónica, el ensayo, la narrativa (tanto de corte realista, como fantástico y autobiográfico) y la poesía.

Y sin contar las manifestaciones literarias que concentran su mirada en topografías del norte y sur del país, es innegable que estas visiones reconstruyen, desde la práctica de espacios aludida por Michel de Certeau, una cartografía literaria y visual de México, el cual también es tomado como punto de referencia para escritores que han migrado por diversas razones, o que buscan sus orígenes familiares en otros confines del mundo. Así, este conjunto cartográfico se enfrenta, por la vía de la manifestación artística (y en nuestro caso, desde la literatura), a otros espacios distantes a fin de conformar un carácter nómada actualmente presente en las letras mexicanas.

\section{Pasos de Fabio Morábito, huellas del nómada}

Como parte de esta corriente y dentro de la literatura contemporánea en México se encuentra Fabio Morábito, escritor e investigador mexicano en cuya obra literaria es posible distinguir líneas temáticas como la experiencia migratoria, el desarraigo territorial y la exploración del mundo desde la escritura y una lengua otra. Nació en 1955 en Alejandría, Egipto, y desde entonces la experiencia migratoria marcaría una parte importante de su visión literaria. Después de sus primeros tres años en Alejandría, viviría parte de su infancia y de su adolescencia en Milán, hasta que a finales de la década de 1960 iría con sus padres a vivir a la Ciudad de México, cambiando forzadamente su italiano por un español con el que aprendería a leer y a interpretar nuevos espacios.

El trayecto entre Alejandría y la Ciudad de México es todavía una larga navegación autobiográfica para el autor, la cual dirige a través de una lengua ajena (y aprendida) que rescata y relata los episodios de una memoria migrante. En buena medida, su obra literaria presenta reflexiones y cuestionamientos sobre aquellos espacios a los que se pertenece y sobre aquellos otros que ya se han perdido. Su experiencia nómada encuentra un desarraigo primero en el conflicto con su idioma materno, el italiano, que ha cedido frente a 
la presencia del español, esa lengua extranjera con la cual realizaría una cartografía de los distintos de espacios urbanos en los que ha transitado su nomadismo.

Tales inquietudes destacan en un conjunto específico de su obra que incluye poesía, cuento y ensayo. Así, el corpus de este análisis se restringe a aquellas publicaciones en las que se aborda una reflexión sobre la pertenencia/desarraigo, sobre la percepción de ciertos espacios reales (o geoespacios urbanos) reescritos desde un crisol imaginario con el que Morábito indaga y elabora su propia biografía. De estas obras, se encuentran el poemario Lotes baldíos (1984), los relatos de También Berlín se olvida (2004), y en menor medida otros poemarios como De lunes todo el año (1992) y Alguien de lava (2002).

En su poemario Lotes baldíos Morábito realiza un registro descriptivo de las ciudades en las que ha vivido: Alejandría, Milán y la Ciudad de México. En este poemario el autor trata de mantener una tensión de cercanía entre esas fronteras lejanas, a las cuales su sentido de pertenencia es ya más fuerte en unas que en otras. Este libro, además de dar por inaugurada la cartografía literaria del escritor, es una medida de exploración y de reconocimiento identitario visto en términos geográficos.

En In limine, primer poema del libro, dice: "Yo nací en una playa / De África, mis padres / Me llevaron al norte, / A una ciudad febril, / Hoy vivo en las montañas, [...] Jadeo mi abecedario / Variado y solitario / Y encuentro al fin mi lengua / Desértica de nómada, / Mi suelo verdadero" (2001: 8), Morábito intenta descifrar, desde la constitución de su espacio matricial hasta el encuentro con un lengua otra, parte de su conformación identitaria. De entre ese abecedario fisurado y sin fronteras precisas emerge una lengua nómada y poética, a través de la cual el escritor rastrea su propia historia. Así, la exploración espacial de Morábito comienza a extenderse para recuperar otros territorios.

Dicha exploración se presenta en el conjunto de poemas llamado Tres ciudades (en el mismo libro) en donde a través de ciertos retratos urbanos resignifica la experiencia de los espacios habitados. El primero de estos tres poemas está dirigido a una vez más a Alejandría, espacio de origen pero también de clausura:

Yo nací lejos / de mi patria, en una / ciudad fundada / en las afueras de África. [...] Yo nací en un 
combate / de lenguas y de orígenes / que sólo tierra adentro / termina, en el desierto, / tal vez por eso un algo / de irrealidad me nutre, / de eterna despedida [...] Alejandría irreal... (ídem: 20-22)

Tanto fundamental como incierta, Alejandría es uno de los puntos de referencia a la que regresarían continuamente las memorias migrantes de Morábito. A su vez, esta geografía materna e iniciática encuentra una relación metafórica con el cambio de lengua en el autor. Sin embargo no sucede lo mismo en Milán, ciudad a la que está dedicado el segundo poema y en donde ciertos episodios de su infancia se diluyen en una sutil declaración de desprecio contra la ciudad misma, rechazando la temprana promesa de un sedentarismo: "Yo regresé a tu ausencia / de puentes y reflejos, / de amplios espacios libres, / marinos. Vuelvo al aire / amargo de tus plazas, / a tus patios estrechos. / No supiste enseñarme / a perderme, te debo / los frutos más oscuros / de mi alma..." (ídem: $30)$.

Pero es en el tercer poema, esta vez dedicado a la Ciudad de México, en donde Morábito retoma su experiencia migratoria como si ella misma fuera una de las pocas pertenencias que le quedan en el trayecto. Aquí es posible ver un discurso de asimilación y pertenencia respecto al espacio, el cual se abordó con la idea de "navegación biográfica" (cf. supra, p. 3). La Ciudad de México es, paradójicamente, el inesperado punto de partida y un nuevo territorio interior en el que posible seguir construyendo la propia identidad.

Un día mi padre dijo / nos vamos, y tú eras / la meta: otra lengua, / otros amigos. No: / los amigos de siempre, / la lengua, la que hablo. / Me he revuelto en tus aguas / volcánicas y urbanas / hasta al fin conocerme, / y si al hablar cometo / los errores de todos, / me digo: soy de aquí, / no me ensuciaste en vano. (ídem: 32 )

En esta declaración, Morábito reconoce el fantasma de sus migraciones. Aquí, la voz poética se consagra a partir de la percepción de un nuevo espacio para así llevar a la práctica su identidad migrante. Pero además se presenta de nuevo un paralelismo entre la experiencia de un espacio otro y de una lengua otra, como sucede en el poema a Alejandría (cf. supra, p. 9). A la Ciudad de México y al español adquirido, Morábito escribe: "A la ciudad 
más grande / vine a dar, a esta urbe / que nunca cicatriza; / la lengua aquí se esconde / bajo tantas heridas / que hablar es lastimarse, / y quien habla mejor / es quien lastima más, / el que mejor se esconde." (ídem: 36)

En el caso de su libro También Berlín se olvida, Morábito realiza una diferente lectura del espacio, como si la imagen de la ciudad de Berlín tuviera superpuesta la imagen de la Ciudad de México: el río Spree que recorre Berlín le hace mirar lo que no tuvo en las otras dos ciudades: "Me crié en una ciudad carente de mar, de ríos y de lagos, y desde hace más de treinta años vivo en otra que, no obstante su glorioso pasado lacustre, no posee ni una gota de agua fluyente" (2004: 57).

Otro punto de contacto que destaca el escritor es el carácter desarticulado de ambas ciudades. "Ahora que ya no hay un Berlín occidental y otro oriental [...] uno se da cuenta de que Berlín es varios Berlines [...] En cierto modo moverse por Berlín es trasladarse de una periferia a otra y Berlín es la prueba de que una gran ciudad puede ser la suma de sus periferias" (ídem: 28) Berlín y la Ciudad de México comparten el mismo registro cartográfico: en un mismo mapa y de forma simultánea, aparecen dos espacios urbanos superpuestos y entremezclados.

El aspecto de la pertenencia, no obstante, queda como un problema sin conclusión definitiva. Sería no a través del español aprendido ni del italiano materno sino, por medio de la lengua literaria, que Morábito ejercerá el papel de un mapmaker (cf. supra, p. 3) con el cual podrá guiar su propia navegación biográfica. Así, en y a partir de la escritura, el autor diseñará sus propios territorios interiores (a través de los espacios geográficos que lo rodean) y dará constitución a su identidad nómada. Un ejemplo que confirma lo anterior es el poema llamado Un viaje a Pátzcuaro, en donde el escritor acentúa su reflexión sobre la relación entre viaje y e identidad:

A los dieciséis años, / sin un motivo claro, / compré un boleto para Pátzcuaro [...] / Llegué al amanecer [...], / la plaza estaba sola, / desiertos los portales, / sólo se oían mis pasos / como en un cuadro de De Chirico [...] / ¿Por qué viajar / para volver, / para probarse, tapándose los ojos? (2012: 83-85) 


\section{Conclusión}

Se ha visitado brevemente una pluralidad de aproximaciones al espacio en México, desde los antiguos códices hasta las formas literarias más actuales; si estas manifestaciones se miran en conjunto, se podrá coincidir con la perspectiva que ofrece Bertrand Westphal en La Géocritique. Réel, fiction, espace ${ }^{10}$ (2007) y así obtener un mapa de representaciones, prácticas y percepciones del espacio en distintas manifestaciones artísticas del país.

Lo anterior constata que homo legens y homo viator dialogan entre sí y con el espacio. Así, se ha visto, no podemos obtener sino meditaciones y ensayos respecto a un Dasein, un estar siendo ahí con consciencia y emoción respecto al espacio, en ese desplazamiento o mudanza que nos permite interactuar con él. Peter Sloterdijk ya se refería a ello con el concepto de metoikesis ${ }^{11}$ en su libro Extrañamiento del mundo (2001). A su vez, en su artículo "Qué nuevo era el Nuevo Mundo", Italo Calvino reflexiona si se descubriera un territorio nuevo, rememorando antiguos sucesos: “...¿sabríamos verlo?, ¿sabríamos descartar de nuestra mente todas las imágenes que estamos acostumbrados a asociar, a la expectativa de un mundo diferente [...] para captar la verdadera diversidad que se presenta a nuestros ojos?" (2001: 21)

La manera en la que cuatro mundos distintos habitan la memoria, la lengua y la identidad de Fabio Morábito, es sólo una posible respuesta dentro de las letras mexicanas. Alejandría, Milán, Berlín y la Ciudad de México configuran la cartografía de periferias y de abecedarios nómadas que el autor asimila y construye mediante la escritura. Esos cuatro territorios interiores le permiten a Morábito llevar registro de su navegación biográfica y de una personal práctica de espacio, la cual realiza a partir de una consciencia nómada que le ayuda a recorrer y a mesurar geografías lejanas entre sí. Quizá al final, esto no sea sino el intento cotidiano para recordar y reconstruir nuestros espacios y las huellas de nuestros trayectos. 


\section{NOTAS}

${ }^{1}$ Cuaderno del nómada es la primera parte de su poemario Partición, escrito entre 1976 y 1982.

${ }^{2} \mathrm{Al}$ respecto, Michel de Certeau señala su interés por atender otro tipo de prácticas espaciales, que se acerquen más a una dinámica antropológica, metafórica y narrativa que permita leer el espacio de otra manera. Así lo expresa en la siguiente cita:

...je voudrais repérer des pratiques étrangères à l'espace 'géométrique' ou 'géographique' [...] Ces pratiques de l'espace renvoient à une forme spécifique d'opérations (des 'manières de faire'), à 'une autre spatialité' (une expérience 'anthropologique', poétique et mythique de l'espace) [...] Une ville transhumante, ou métaphorique, s'insinue ainsi dans le texte clair de la ville planifiée et lisible. (1990: 142) [...quisiera identificar las prácticas extranjeras al espacio 'geométrico' o 'geográfico' [...] Esas prácticas del espacio reenvían a una forma específica de operaciones (de 'manera de hacer'), a 'otra espacialidad' (una experiencia 'antropológica', poética y mítica del espacio) [...] Una ciudad transhumante, o metafórica, se insinúa así en el texto claro de la ciudad planificada y legible. (Traducción mía)].

${ }^{3}$ Robert Tally recupera un conjunto de referencias para proyectar el concepto de mapmaker, es decir, la idea de un "escritor de mapas" o individuo que realiza precisamente un mapeo del espacio que lo rodea. Para ello, Tally aborda obras como Space and Place: The Perspective of Experience (1977) de Yi-Fu Tuan, Postmodernism, or, the Cultural Logic of Late Capitalism (1991) de Fredric Jameson, Thirdspace: Journeys to Los Angeles and Other Real-and6 Imagined Places (1996) de Edward W. Soja, Y Maps of the Imagination: The Writer as Cartographer (Zûư) de Peter Turchi.

4 Una de las premisas del artículo es: "The personal navigation through the diverse constellation of belonging consists in more or less conscious choices when it comes to the constructions of the self, to new normative orientations, to negotiations and positionings..." (Pfaff-Czarnecka 2013 : 10) [La navegación personal a través de diferentes constelaciones de pertenencia consiste elecciones más o menos conscientes cuando se trata construcciones de sí mismo, de nuevas orientaciones normativas, de negociaciones y emplazamientos... (Traducción mía)]. La autora establece la diferencia de "pertenecer a" y "pertenecer con": ambos procesos dan nuevas experiencias de autoconocimiento con diversas fronteras y esferas como la étnica, la familiar o la religiosa.

${ }^{5}$ Robert Tally retoma en Spatiality este concepto: "The spaces represented in the novel cannot be the same as the "real" space, what Barbara Piatti calls geospace in contrast to the imagined space in literary texts [...] of a city or country." (apud Tally, 2013 : 52) [Los espacios representados en la novela no pueden iguales a los espacios 'reales', a los que Barbara Piatti llama geoespacio en contraste con el espacio imaginado de una ciudad o país en los textos literarios. (Traducción mía)]. La obra en la que Piatti da este concepto es Die Geographie der Literatur: Schauplätze, Handlungsräume, Raumphantasien (Göttingen, Wallstein Verlag, 2008).

${ }^{6}$ Sobre al tema, sugiero dos artículos: "La perception de l'espace dans les sociétés précolombiennes du Mexique d'après les Codex" (1985) de Alain Musset (en Espace géographique, tomo 14, no. 1, pp. 49-57) y "Le Mexique central à travers le Codex Xolotl et Alva Ixtlilxochitl : entre l'espace préhispanique et l'écriture coloniale" (2012) de Patrick Lesbre (en e-Spania [en ligne], no. 14, decembre).

${ }^{7}$ Los artistas son Edouard Rivière, escenógrafo y escritor; Juan R. Navarro, impresor; José Antonio Decaen, editor y litógrafo; Carlos Hipólito Serán, autor dramático; y Casimiro Castro, artista plástico.

${ }^{8}$ Este texto apareció en un periódico llamado La chinaca. Periódico escrito única y esclusivamente (sic) para el pueblo, cuyo tiraje inició en abril de 1862.

${ }^{9}$ La lista es exhaustiva y se corre el riesgo de omitir referencias importantes. Basta decir que el acercamiento al espacio urbano de la ciudad de México se dio incluso en grupos muy definidos en su idea sobre literatura, como los Contemporáneos (1927-1932), con obras como La llama fría (1925) de Gilberto Owen, Dama de Corazones (1928) 
de Xavier Villaurrutia, o El joven (1928) de Salvador Novo. Al respecto, sugiero el estudio que Vicente Quirarte presenta en Amor de ciudad grande (2011).

${ }^{10}$ Bertrand Westphal señala, sobre la geocrítica, lo siguiente:

Il appartient à la géocritique de constituer le lieu en tópos átopos, de l'intégrer dans 'le flux de la variation imaginaire des transformations possibles' (Eugen Fink, De la phénomenologie, 1974, p.106). Il appartient également à la géocritique de tirer profit des enseignements fugaces des arts mimétiques pour mieux entendre le monde, pour saisir [...] les espaces humains dans leur mouvance.... (2007: 236-237). [Pertenece a la geocrítica constituir el lugar en tópos átopos, de integrarlo en 'el flujo de la variación imaginaria de transformaciones posibles'. Pertenece igualmente a la geocrítica el beneficiarse de las fugaces enseñanzas de las artes miméticas para comprender mejor el mundo, para tomar [...] los espacios humanos en su movimiento... (Traducción mía)].

${ }^{11}$ Peter Sloterdijk explica así el término:

La expresión metoikesis, la mudanza de casa, el cambio de domicilio, el traslado a otra forma de estar en sí, entendida como metáfora de la muerte y título de la última metamorfosis, entraña una alusión a la honda movilidad de la existencia humana que está más implicada como cambio de lugar a la misma escala y en el mismo elemento. Quien se muda [...] 'de aquí a allá', no sólo es un turista y un viajante, sino un cambista de elementos, un emigrante entre diversos estados físicos o dimensiones del ser. (2001: 89). 


\section{Bibliografía}

Calvino, Italo (2001), Colección de arena, Barcelona, Siruela.

Certeau, Michel de (1990), L'invention du quotidien. 1. Arts de faire, France, Gallimard [1980].

Morábito, Fabio (2001), Lotes baldíos, (Terrains vagues), trad. Fabienne Bradu, Québec, Écrits des forges/Aldus [1984].

-- (2004), También Berlín se olvida, México, Tusquets.

-- (2012), Ventanas encendidas. Antología poética, España, Visor.

Pfaff-Czarnecka, Joanna (2013), "Multiple belonging and the challenges to Biographic Navigation", en ISA eSymposium for Sociology, consultado el 16 de junio de 2017, en pub.uni-bielefeld.de/publication/2604198

Segovia, Tomás (2000), Poesía (1943-1997), México, FCE. [1998]

Sloterdijk, Peter (2001), Extrañamiento del mundo, trad. Eduardo Gil Vera, Valencia, Pretextos.

Tally, Robert (2013), Spatiality, New York, Routledge.

Westphal, Bertrand (2007), La Géocritique. Réel, fiction, espace, France, Éditions de Minuit.

Adalberto Mejía es doctorando en Estudios en Lengua Romance (especialidad literatura hispanoamericana) de la Universidad Paul Valéry-Montpellier III, bajo la dirección del Dr. Karim Benmiloud. Ha participado dentro de congresos en España, Francia, Hungría, México, Polonia y República Checa. Ha elaborado tesis sobre la literatura fantástica de Francisco Tario (maestría) y Las ciudades invisibles de Italo Calvino (licenciatura). En 2012 realizó una 
estancia en la Universidad Autónoma de Barcelona con el Dr. David Roas. Tiene publicaciones en el volumen de Topologías literarias. El espacio en la literatura hispánica de la Edad Media al siglo XXI (Madrid, 2017), en Brumal. Revista de investigaciones sobre lo fantástico, y en colecciones universitarias de Morelia, Guadalajara y Monterrey. 